by the interaction of $\mathrm{C} 3 \mathrm{~b}$ with factors $\mathrm{B}$ and $\mathrm{D}$ in the presence of $\mathrm{Mg}^{++} .{ }^{15}$ Factor $\mathrm{B}$ is consumed not only in the alternative pathway but also in the C $3 b$ feedback system, whereas factor $D$ is probably not significantly consumed in either. A functional deficiency of factor $B$ of the degree we have shown in patients with sickle cell anaemia could therefore restrict both alternative pathway and C3b feedback activity.

This deficiency may be an important limiting factor in the generation of $\mathrm{C} 3 \mathrm{~b}$, and thus in opsonification, and may have an importation bearing on the susceptibility of patients with sickle cell anaemia to infection. Reduced levels of factor B are compatible with its defective synthesis, excessive degradation, perhaps by chronic activation of the pathways, or possibly inhibition. The restoration of opsonification by sera of patients with sickle cell anaemia to normal by the addition of normal serum $^{6}$ makes the last possibility the least likely. Further studies are needed to distinguish between these possibilities and to clarify the relation between this deficiency and other features of the disease.

This work was supported by the Wellcome Trust, and also by Merck, Sharp and Dohme (WI). We thank Miss D Grennan and Mr G Frampton for technical help, Drs M Hobart and L Halbwachs for their advice, and Dr G Serjeant and Dr D King for their help.
Requests for reprints should be addressed to G R V H.

\section{References}

${ }^{1}$ Seeler, R A, Metzger, W, and Mufson, M A, American fournal of Diseases of Childhood, 1972, 123, 8.

2 Konotey-Ahulu, F I D, Lancet, 1971, 2, 1255.

${ }^{3}$ Robinson, M G, and Watson, R J, New England fournal of Medicine, 1966, 274, 1006.

${ }^{4}$ Eeckles, R, Gatti, F, and Renoirte, A M, Nature, 1967, 216, 382.

5 Winkelstein, J A, and Drachmann, R H, New England fournal of Medicine, $1968,279,459$.

${ }^{6}$ Johnson, R B, Newman, S L, and Struth, A G, New England fournal of Medicine, 1973, 288, 803.

${ }^{7}$ Gotze, O, and Muller-Eberhard, H J, fournal of Experimental Medicine, 1971, 134, suppl 2, p 90.

${ }^{8}$ Fearon, D T, Austen, K F, and Ruddy, S, fournal of Experimental Medicine, 1974, 139, 355.

${ }^{9}$ Muller-Eberhard, H J, and Gotze, O, fournal of Experimental Medicine, $1972,135,1003$.

${ }^{10}$ Goodkofsky, I, and Lepow, I H, fournal of Immunology, 1971, 107, 1200.

${ }^{11}$ Fearon, D T, Austen, K F, and Ruddy, S, fournal of Experimental Medicine, 1973, 138, 1305.

${ }^{12}$ Martin, A, et al, Immunochemistry, in press.

${ }^{13}$ Pillemer, L, Blum, L, and Lepow, I H, Science, 1954, 120, 279.

${ }^{14}$ Soter, N A, Austen, K F, and Gigli, I, fournal of Investigative Dermatology, 1974, 63, 219.

${ }^{15}$ Nicol, P A, and Lachmann, P J, Immunology, 1973, 24, 259.

\title{
Autologous immune complex nephritis associated with sickle cell trait: Diagnosis of the haemoglobinopathy after renal structural and immunological studies
}

\author{
TAKESHI OZAWA， MYRON F MASS， STEPHEN GUGGENHEIM， JOSE STRAUSS, \\ RAWLE M MCINTOSH
}

British Medical fournal, 1976, 1, 369-371

\section{Summary}

A renal tubular epithelial antigen (RTE)-anti-RTE autologous immune complex nephritis associated with sickle cell anaemia (SS) has been reported, but immune complex nephritis has never been described in patients with sickle cell trait (SA). During investigation of a child with "asymptomatic proteinuria" cryoprecipitable complexes of RTE-anti-RTE were detected in the seru m and granular deposits of RTE, immunoglobulins, and complement localised on the glomerular basement membranes. Morphological and ultrastructural studies showed increased mesangial matrix, sickled red blood cells in the glomeruli and vessels, and tubular and interstitial abnormalities. These findings prompted haemoglobin electrophoretic studies, which showed previously undiagnosed haemoglobin $\mathrm{SA}$ in this patient

University of Colorado Medical Centre, Denver, Colorado 8022 TAKESHI OZAWA, MD, fellow in nephrology

MYRON F MASS, MD, fellow in clinical immunology

STEPHEN GUGGENHEIM, MD, assistant professor of medicine and pathology

RAWLE M MCINTOSH, MD, professor of paediatrics and medicine

Department of Paediatrics, University of Miami School of Medicine, Miami, Florida

JOSE STRAUSS, MD, professor of paediatrics and her family. These observations suggest that nephritis mediated by similar immunopathogenic mechanisms may be associated with SS and SA haemoglobinopathy. Under some conditions patients with sickle cell trait may experience haemodynamic and oxygenation abnormalities, which may be aetiological factors in the immune complex nephritis associated with SS disease.

\section{Introduction}

Various renal abnormalities have occurred in association with sickle cell (SS) disease. ${ }^{1-3}$ Recently we reported an immune deposit nephropathy associated with sickle cell disease ${ }^{4}$ and showed an autologous immune complex pathogenesis secondary to glomerular deposition of circulating complexes of renal tubular epithelial antigen (RTE) and antibody in nephritis associated with this disease. ${ }^{6} 7$ Although haematuria, tubular defects, and even the nephrotic syndrome have been reported with sickle cell trait (SA), ${ }^{2}{ }^{8} 9$ an immune deposit glomerulonephritis has not been reported. We report here a patient with proteinuria in whom the localisation of glomerular RTE in association with immunoglobulins and complement, the renal histological findings, and the detection of serum cryoproteins containing RTE and RTE antibody led to the diagnosis of sickle cell trait.

\section{Case Report}

On routine screening of her family because her sister had membranous nephropathy associated with chronic hepatitis B antigen- 
aemia, a 16-year-old Black girl was found to have proteinuria. The patient was apparently healthy. She had never had hypertension, jaundice, abdominal pain, arthralgia, oedema, haematuria, or proteinuria.

Laboratory studies at the University of Colorado Medical Centre before and after her admission included urine analyses, measurements of urinary protein excretion, serum electrolytes, creatinine, blood urea nitrogen, and creatinine clearance, blood counts, and liver function tests. Serum total haemolytic complement and components and immunoglobulins were measured. Serum was studied for HBsAg and antibody (HBsAb), and she was found, together with a brother and another sister, to have hepatitis B surface antigenaemia. Cryoproteins were isolated and characterised, ${ }^{6} 1011$ and they were studied for the presence of RTE and HBsAg and HBsAB; she was found to have cryoproteinaemia.

Because of these findings she was admitted to the centre, where physical examination showed no abnormalities and a history failed to elicit any evidence of sickle cell disease in the family. An excretory urogram and coagulation studies showed nothing abnormal and a percutaneous renal biopsy was performed.

\section{IMMUNOLOGICAL STUDIES}

Renal tissue obtained at biopsy was fixed in formalin for light microscopy or glutaraldehyde for electron microscopy. The remainder was snap frozen, and $4-\mu \mathrm{m}$ sections were used for immunohistological studies. Immunofluorescent studies were performed using fluorescein isothiocyanate (FITC) conjugated antisera to human IgG, IgM, IgA, Clq, C3, C4, C3PA, serum albumin, fibrinogen, aggregated human IgG, and RTE. ${ }^{7}$ Staining for RTE was also performed after treatment of the sections with $0.01-M$ citrate buffer pH 3.2 and after absorption of the antisera with RTE. Sections were also stained with FITC rabbit antisera to $\mathrm{HBsAg}$ as well as FITC-conjugated globulins from the serum of a patient with a haemagglutination titre of 1/356 of antibody to $\mathrm{HBsAg}$ of the same subtype. Immunofluorescent staining of sections with antibody to HBsAg was also performed after sections had been treated with $0 \cdot 01-M$ citrate buffer.

The patient's cryoprotein and serum globulins were conjugated with FITC and used to stain normal human and rat kidney and jejunal mucosa and sections of the patient's kidney before and after treatment with citrate buffer. Immunohistology using the patient's FITC globulin was performed before and after absorption with RTE.

Because of the renal biopsy findings and cryoprotein content haemoglobin electrophoresis was performed on her family.

RESULTS

The results of complete blood count, serum electrolytes, and liver function were all normal. Routine urine analysis showed a specific gravity of $1.019, \mathrm{pH}$ of 5 , and a trace of protein. Examination of the urinary sediment showed no cellular elements. Urinary protein excretion varied from $250 \mathrm{mg} / 24 \mathrm{~h}$ to $1.7 \mathrm{~g} / 24^{\prime} \mathrm{h}$. Creatinine clearances ranged from $84 \mathrm{ml} \mathrm{min}^{-1} 1.73 \mathrm{~m}^{-2}$ to $100 \mathrm{ml} \mathrm{min}^{-1} 1.73 \mathrm{~m}^{-2}$.

Cryoproteins were isolated from the serum and contained $\mathrm{IgG}$ $200 \mathrm{mg} / \mathrm{l}, \operatorname{IgM} 6 \mathrm{mg} / \mathrm{l}$, and IgA $68 \mathrm{mg} / \mathrm{l}$. The supernatant serum after cryoprecipitation contained $\operatorname{IgG} 13.75 \mathrm{~g} / 1, \operatorname{IgM} 1.7 \mathrm{~g} / \mathrm{l}$, and IgA $3.45 \mathrm{~g} / \mathrm{l}$. HBsAg was detected in a titre of $1 / 4$ in the cryoprotein and $1 / 8$ in the supernatant serum. HBsAb was not detected in either the cryoprotein or the supernatant serum. Immunoreactive RTE and anti-RTE was found in the cryoproteins. Total haemolytic complement and complement components were normal.

Light microscopy of the kidney showed increased mesangial matrix (fig 1) and apparently sickled red blood cells in the glomeruli. The tubules were widely separated and contained very occasional eosinophilic casts. The interstitium contained abundant collagen. The vessels were congested and some of the red blood cells appeared sickled (fig 2). Electron microscopy showed also electron-dense material in the mesangium with sickled red blood cells in the capillary lumen.

Immunohistological studies on the patient's kidney showed IgG, IgM, IgA, C1q, C3, C4, and RTE in a granular pattern along the glomerular basement membrane and in the mesangium (fig 3). IgG and $\mathrm{C} 3$ were also present in the proximal tubules. RTE was prominent along the proximal tubules. Immunofluorescent staining of the glomerulus with anti-RTE was more prominent after treatment of the tissue sections with citrate buffer. Immunofluorescent local- isation of RTE was no longer detectable after absorption with RTE. HBsAg, albumin, and fibrinogen could not be localised by the immunofluorescent techniques used. Studies using FITC-conjugated cryoproteins and globulins isolated from the patient's serum stained the patient's glomeruli and proximal tubules. Glomerular staining was in a diffuse granular pattern and was accentuated after treatment

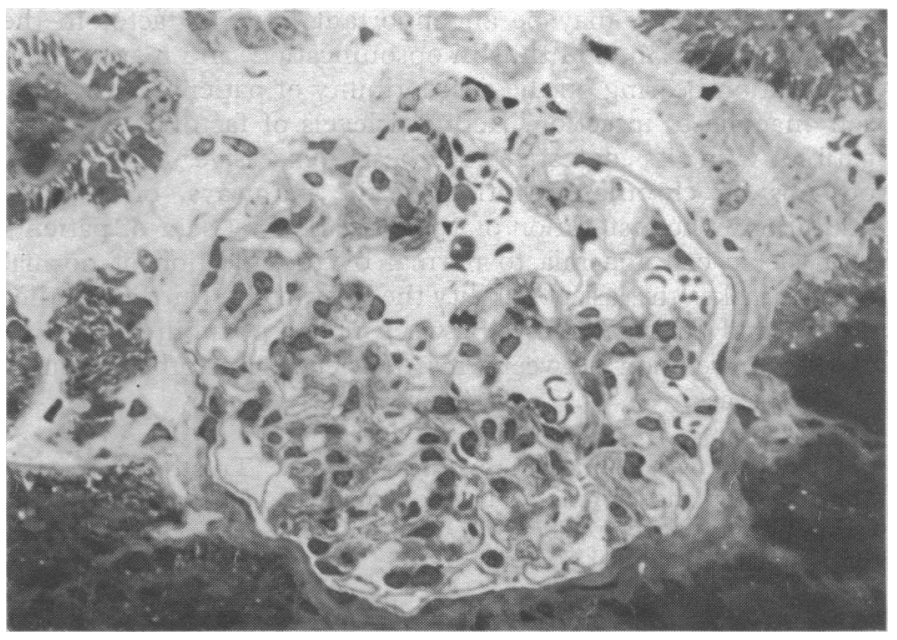

FIG 1-Section of patient's kidney stained with haematoxylin and eosin showing increased mesangial matrix and sickled red blood cells in glomerulus.

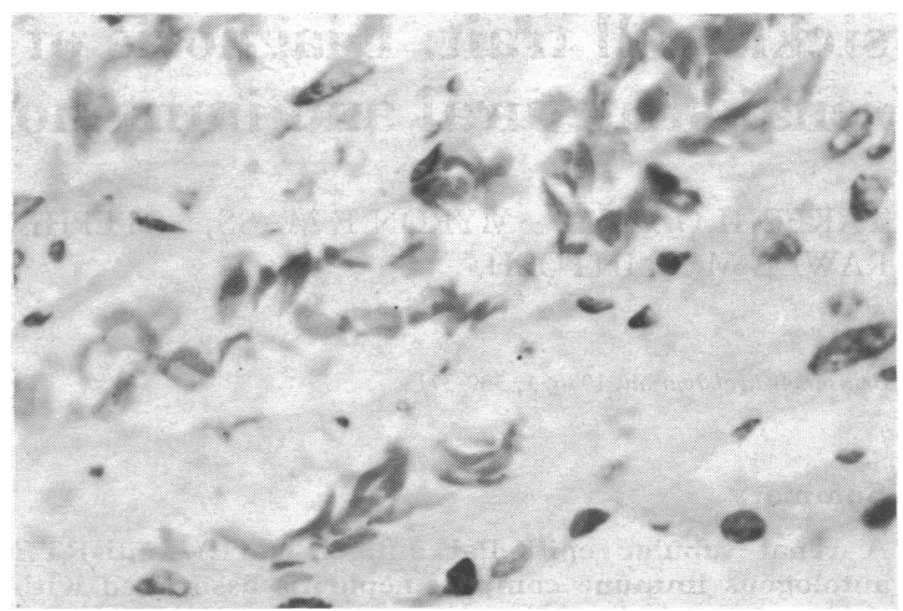

FIG 2-Section of patient's kidney stained with haematoxylin and eosin showing sickled red blood cells in vessels.

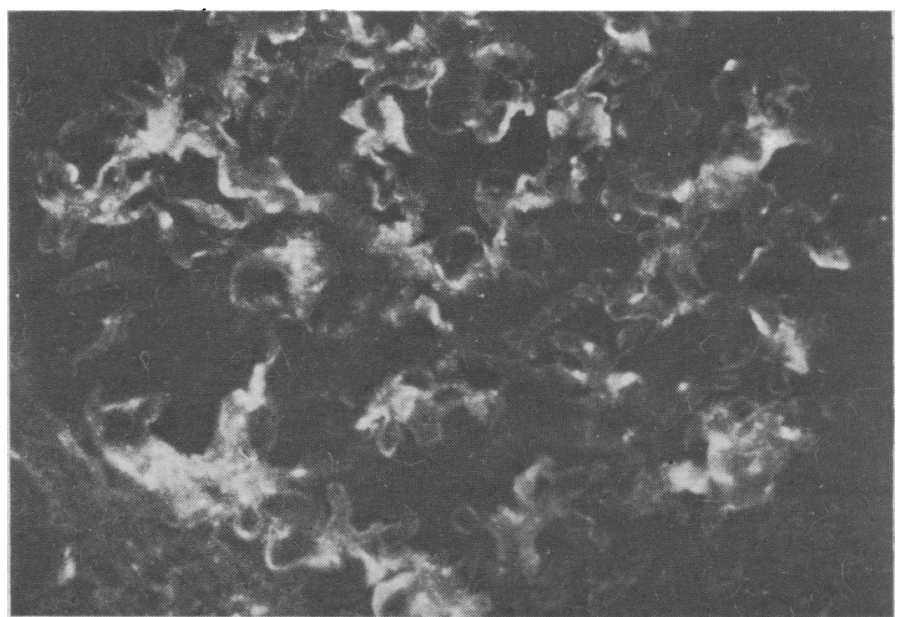

FIG 3-Patient's kidney section stained with FITC-conjugated antiserum to human IgG showing immunofluorescent deposits along glomerular basement membrane and in mesangium. 


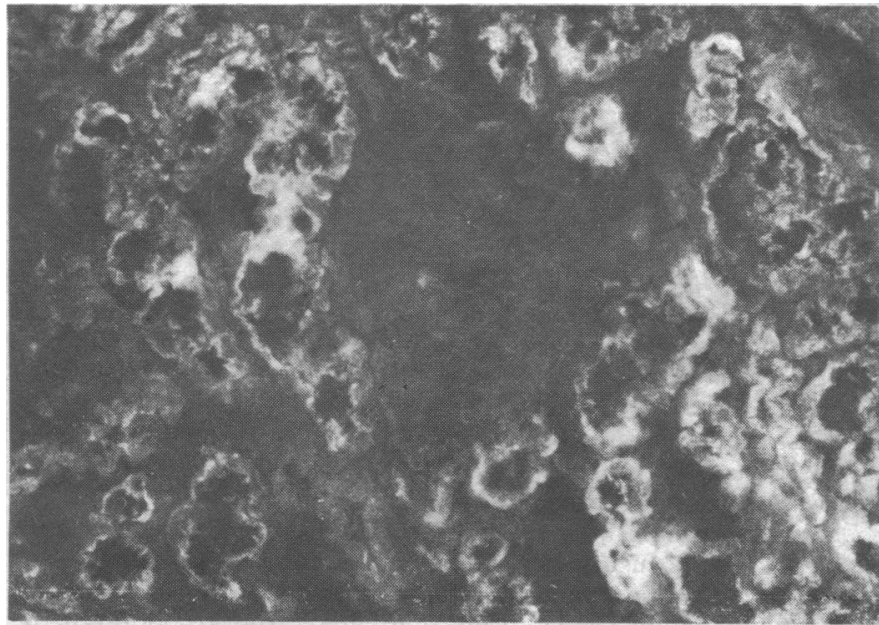

FIG 4-Section of normal human kidney stained with FITC-conjugated cryoproteins isolated from patient showing immunofluorescence in renal tubules but no desposits in glomeruli.

of the sections with citrate buffer. These conjugates also stained normal human and rat renal proximal tubules and jejunal mucosa (fig 4) but not renal glomeruli of normal human and rats. The staining was not detectable after absorption with RTE.

Haemoglobin electrophoresis performed on the family members showed $\mathrm{Hb} \mathrm{SA}$ in the patient, her mother, and two siblings and $\mathrm{Hb} \mathrm{AA}$ in three other siblings. The father and one brother were not available for study.

\section{Discussion}

The association between the presence of haemoglobin S (SS, SC, and SA) and renal abnormalities is well known, ${ }^{1-4} 89$ and several patients with SS disease have immune deposit nephritis. ${ }^{5-i}$ We have provided evidence for an autologous immune complex pathogenesis (PTE-anti-RTE mediated) in some of these patients. ${ }^{6}{ }^{7}$ Immune complex nephritis has not, however, been suggested to occur in patients with sickle cell trait. ${ }^{12}$ Necropsy studies in these patients, particularly in those who have died unexpectedly, have shown histological evidence of recent crises. ${ }^{12}$ Sickle cell crisis is usually associated with drinking alcohol, acidosis, hypoxaemia, exercise, high altitude, or the presence of reducing agents, but glomerular lesions in patients with the trait have been limited to the presence of sickled cells in the glomerular capillaries. Even patients who also have the nephrotic syndrome have no glomerular lesions. ${ }^{9}$

The finding of sickled red blood cells in our patient suggested the presence of a haemoglobinopathy. The localisation of RTE in association with immunoglobulin and complement components together with the presence of cryoproteins with anti-RTE and RTE suggested an autologous immune complex pathogenesis similar to that observed in SS disease. The role of $\mathrm{HBAg}$ in the renal disease is unclear, since this antigen was not localised in the glomeruli.

These observations suggest that patients with sickle cell trait may develop an immune complex glomerular disease similar to that in patients with SS disease. Since these patients do have sickling phenomena and crises under various conditions the same mechanisms may be involved in the pathogenesis of the glomerular findings. Prospective and retrospective statistical, morphological, immunohistological, and immunological studies need to be performed to examine the associations observed here; the possibility of a chance association cannot be excluded. Apart from our cases of sickle cell anaemia RTE has been implicated in only a few cases of idiopathic membranous nephropathy, ${ }^{13}$ renal cell carcinoma, ${ }^{14}$ and gold and mercurial nephrosis in man and experimental animals and in one case of nephropathy associated with renal vein thrombosis. ${ }^{15}$ There was no evidence of any of these conditions in our patient. Furthermore, we have routinely been looking for circulating and glomerular-bound RTE-anti-RTE complexes in patients with glomerulonephritis and have detected these only rarely, usually when there has been tubular damage.

Although we found cryoprecipitable serum immune complexes of $\mathrm{HBsAg}$ and $\mathrm{HBsAb}$ in this patient, $\mathrm{HBsAg}$ was not localised in the glomerulus and cannot be implicated in the immune complex nephropathy. Furthermore, the morphology was not characteristic of that observed in nephropathy associated with chronic hepatitis antigenaemia. ${ }^{1617}$ Possibly the physiochemical properties of HbsAg-Hbs Ab immune complexes were of such a nature that they did not facilitate glomerular localisation.

Our findings, although complicated by the presence of hepatitis B surface antigenaemia, indicate that RTE may have a role in the pathogenesis of the renal lesion. Since an autologous immune deposit nephropathy occurs with SS disease it is not unreasonable to postulate a similar mechanism in some cases of nephritis associated with sickle cell trait.

This work was supported by grants in aid from the Rocky Mountain Kidney Foundation, Colorado Heart Association, USPHS GRS 5 SO1 RR 05357, NIH General CRC Grant RR 69, Colorado Sickle Cell Treatment Centre House Bill No 1578, and the Miami Dolphins Wives Club. Dr McIntosh is an Established Investigator of the American Heart Association.

Requests for reprints should be addressed to Dr Rawle M McIntosh, Box C233, University of Colorado Medical Centre, Denver, Colorado, 80220.

\section{References}

1 McCoy, R C, Laboratory Investigation, 1969, 21, 85.

2 Schlitt, L E, and Keitel, H G, American Fournal of Medical Science, 1960, $152,773$.

${ }^{3}$ Sweeney, M F, Dobbins, W T, and Etteldorf, J N, fournal of Pediatrics, 1962, 60, 42 .

4 Strauss, J, et al, Clinical Research, 1974, 22, 98a.

5 Pardo, V, et al, American fournal of Medicine, in press.

6 Strauss, J, et al, Annals of Internal Medicine, 1974, 81, 114

i Strauss, J, et al, American fournal of Medicine, 1975, 58, 382.

${ }^{8}$ Bennett, M A, Heslop, R W, and Meynell, M J, British Medical fournal, $1967,1,677$.

${ }^{9}$ Elfenbein, B, et al, American fournal of Pathology, 1974, 77, 357.

10 McIntosh, R M, Kaufman, D B, and Kulvinskas, C, International Archives of Allergy and Applied Immunology, 1971, 41, 700.

${ }_{11}$ McIntosh, R M, et al,Quarterly fournal of Medicine, 1975, 44, 286.

12 Jones, S R, Binder, R A, and Monowho, E M, New England fournal of Medicine, 1970, 282, 323.

13 Naruse, T, et al, fournal of Allergy and Clinical Immunology, 1974, 54, 311.

14 Ozawa, T, et al, Quarterly fournal of Medicine, 1975, 44, 563.

15 Ozawa, T, et al, Archives of Pathology, in press.

16 Kohler, P F, et al, Annals of Internal Medicine, 1974, 81, 448.

${ }^{17}$ Brzosko, W J, et al, Lancet, 1974, 2, 477. 